\title{
Traditional ecological knowledge and sustainability of ecosystem services on islands: A case study of Shinan County, Jeollanamdo, Republic of Korea
}

\author{
Jae-Eun KIM \\ Institution for Marine and Island Cultures, Mokpo National University \\ ecokimje@gmail.com
}

Publication Information:

Received 18 December 2018, Accepted 2 May 2019, Available online 1 June 2019

DOI: 10.21463/jmic.2019.08.1.03

\begin{abstract}
The importance of traditional ecological knowledge to the sustainability of ecosystem services is obvious when realizing that such knowledge, handed down through generations, is essentially about how to ensure the continuous utilization of limited natural resources. In other words, traditional ecological knowledge provides a way to sustain the value of ecosystem services. In existing research on the value of ecosystem services, however, the role of traditional ecological knowledge remains largely unaddressed. For traditional ecological knowledge to remain available in local communities, it is necessary that elderly community members can pass it on to younger generations. Worryingly, this knowledge transmission is often hampered by modern-day demographic changes that see the working-age population decrease and the elderly population increase. This paper aims to investigate the impact of traditional ecological knowledge on the value of ecosystem services by accounting for the demographic composition of communities, taking the islands in Shinan County, Jeollanamdo, Republic of Korea, as a case study. The varying degrees in which the 13 investigated islands in Shinan County are experiencing the aforementioned demographic changes affect the sustainability of their ecosystem services. To incorporate the demographic composition into the valuation of ecosystem services, a weight factor was calculated being the ratio of the working-age population to the elderly population. The study results identified the islands Aphaedo and Jido, both areas with a high value of ecosystem services, as having the highest sustainability. Although having a relatively low value of ecosystem services, the island Imjado ranked third in terms of sustainability due to a relatively good demographic composition. It is reasonable to say that the study took a very simple approach by using only a single weight factor based on the demographic composition of communities to quantify the possibilities of transfer and acquisition of traditional ecological knowledge in those communities. Despite this limitation, however, the paper is expected to facilitate the necessary indepth discussion of the role of traditional ecological knowledge in sustaining the value of ecological services.
\end{abstract}

\section{Keywords}

Sustainability, islands, population, weight factor, demographic composition, knowledge transmission 


\section{Introduction}

Since the research began in the 1970s various aspects of ecosystem services have been studied, although it took until 1981 before the terminology was established and until the 1990s and the 2000s for it to become an active research topic. Some of the research has received great attention. The book "Nature's Services: Social Dependence on Natural Ecosystems" (Daily et al. 1997) described how much human life is affected and closely related to nature. Twenty years later, Costanza et al. (2017) conducted a meta-analysis of data from existing literature, distinguishing 16 biomes of the world and including 17 types of ecosystem services to assess the "value of the world's ecosystem services and natural capital". It estimated the total value at an average of US\$33 trillion per year, within a range of US\$16-54 trillion per year. This is the minimum predicted value considering the characteristics of nature, which is mostly non-market value and uncertain.

Ecosystem services are based on the idea that the current system in which we live is based on the benefits of nature. All basic things, such as breathing air, drinking water, and food ingredients, are obtained from the ecosystem, and its value on a global scale needs to be managed more effectively and used as policy. Ecosystem services are being explored to make effective proposals for policies that are based on the development of human life, such as climate change due to the destruction of ecosystems as well as development and conservation issues.

The island ecosystem is highly vulnerable to diverse environmental changes. Small islands are particularly susceptible to these changes (Balzan et al. 2016, Kim 2016). Islands can achieve sustainable life by responsibly utilizing their limited amount of resources from a limited space. It is known for long that life on islands is in closer harmony with nature than on the mainland, with Traditional Ecological Knowledge (TEK) playing a key role in adapting to the island's ecosystem and living sustainably. In fact, it has been hypothesized that the collapse of Easter Island - in terms of how traces of mankind disappeared from the island - was due to the destruction of the island ecosystem by excessive consumption of natural resources. On islands, the amount and quality of ecosystem services are of greater and more direct importance than on the mainland.

It is self-evident that the sustainability of ecosystem services depends on how people use resources. In Korean islands, villagers often work together in the collection and distribution of resources, such as coastal algae, and rely on traditional harvesting methods to ensure that the whole village can continue to use it while managing the collection sites (Kim 2010; Park 2001; Song 2018). Eventually, TEK plays an essential role in safeguarding the island's ecosystem services. However, in the research on ecosystem services there is little attention for the role of TEK (Balzan et al. 2018).

To let TEK form the basis of maintaining ecosystem services, the demographic composition of the local community has to be sufficiently balanced in terms of younger and older age segments. This is because the transfer of TEK from older community members to younger ones - those of working age - needs to be possible for the knowledge to remain available (Hong et al. 2018). However, the population of South Korea is rapidly declining and ageing, and these trends are most severe on small islands. This not only poses a direct threat to the actual preservation of TEK but it will also negatively affect the sustainability of ecosystem services.

This paper introduces a simple method to quantify the sustainability of ecological services based on the demographic composition of the population with regard to its ability to transfer TEK. The method is illustrated for the case of Shinangun, a county consisting of only islands, using data on ecosystem services values for land use and land cover calculated 
in an earlier study (Kim 2014). As such, the paper presents a way to address not only the value of ecosystem services but also their sustainability.

\section{Ecosystem Services in Shinan Country}

Located along the southwestern coast of Korea, Shinan County is an administrative area made up of islands belonging to smaller administrative areas ( 12 'myeon' of 2 'eup'). The three main islands (Jido, Aphaedo, Jeungdo) are accessible by bridges from the mainland. Aphaedo was the first to become accessible via Aphae Bridge in 2008, Jido was connected to the mainland in 2010, after which Jeungdo was connected by bridge to Jido. Shinan Country is known for having more traditional culture than other places because it is made up of only islands (National Institute of Biological Resources 2018). Except for Heuksando and Hongdo, which are famous for the Dadohaehaesang National Park, the islands' main economic activities are based on agriculture and fisheries (Kim 2016). However, Shinan County is an area where farming and fishing villages currently face problems such as population decline and population aging. According to the "Prediction of the Korean Local Population in 2018" (Lee 2018), the islands in Shinan County are at a very high risk of complete depopulation. In "The value of the world's ecosystem services and natural capital", Costanza et al. (2017) suggested a classification of 17 types of ecosystem services. As stated by Kubiszewski et al. (2013), various studies and papers have tried to calculate the value of ecosystem services. Costanza et al. (1997) presented a methodology for basic value calculation:

$$
E S V=\sum_{k} \times \sum_{f}\left(A_{k} \times V C_{k}\right)
$$

$A_{K}$ : Area by type of land use and land cover, $V C_{k}$ : Ecosystem services value coefficient 
Table 1. ESV coefficient according to land use and land cover by Costanza et al. (1997)

\begin{tabular}{|c|c|c|}
\hline Land use \& land cover categories & Equivalent biome & ESV coefficient (US\$ ha $^{-1} /$ year) \\
\hline Residential area & \multirow[t]{6}{*}{ Urban } & \multirow[t]{6}{*}{0} \\
\hline Industrial area & & \\
\hline Commercial area & & \\
\hline Recreational area & & \\
\hline Transport service area & & \\
\hline Public facilities area & & \\
\hline Rice paddy field & \multirow[t]{5}{*}{ Cropland } & \multirow[t]{5}{*}{92} \\
\hline Upland field & & \\
\hline Green house field & & \\
\hline Orchard & & \\
\hline Other agricultural area & & \\
\hline Broadleaved forest & \multirow[t]{3}{*}{ Temperate Forest } & \multirow[t]{3}{*}{302} \\
\hline Conifer forest & & \\
\hline Mixed forest & & \\
\hline Natural grassland & \multirow[t]{3}{*}{ Grassland } & \multirow[t]{3}{*}{232} \\
\hline Golf course & & \\
\hline Other grassland & & \\
\hline Inland wetland & Watershed & 19,580 \\
\hline Coastal wetland & Tidal flat & 9,990 \\
\hline Mining area & \multirow[t]{2}{*}{ Desert } & \multirow[t]{2}{*}{0} \\
\hline Other barren land & & \\
\hline Inland water surface & Lake/River & 8,498 \\
\hline
\end{tabular}

As shown in Table 1, tidal flats have the second highest ESV coefficient, more than 30 times higher compared to forests. Shinan County's ecological services by the coefficient of Costanza et al. (1997) are shown in Table 2 (Kim 2014). The main land uses/covers in Shinan County are tidal flats, croplands, and temperate forests. The tidal flats in Shinan County are the most extensive coastal wetlands in Korea and therefore they have the highest value of ecosystem services given by tidal flats in the country. In Shinan County, Aphaedo has the largest tidal flat area and consequently the value of its ecosystem services is the highest. 
Table 2. ESV according to land use and land cover types in Shinan County ${ }^{1}$

\begin{tabular}{|l|l|l|l|l|l|l|l|l|l|}
\hline $\begin{array}{c}\text { District- } \\
\text { myeon }\end{array}$ & Urban & Cropland & \multicolumn{1}{|c|}{$\begin{array}{c}\text { Temperate } \\
\text { Forest }\end{array}$} & Grassland & $\begin{array}{c}\text { Inland } \\
\text { Wetland }\end{array}$ & Tidal flat & $\begin{array}{c}\text { Desert/Barren } \\
\text { land }\end{array}$ & \multicolumn{1}{|c|}{$\begin{array}{c}\text { Fresh Water } \\
\text { Surface }\end{array}$} & \multicolumn{1}{|c|}{ ESV } \\
\hline Dochodo & $1,050.10$ & $16,956.90$ & $19,907.00$ & 140.7 & 88.5 & $15,659.60$ & 327.5 & $1,779.60$ & $55,909.90$ \\
\hline Biguemdo & $1,239.90$ & $17,251.60$ & $18,006.10$ & $1,142.20$ & - & $15,985.10$ & $1,864.50$ & $2,752.10$ & $58,241.50$ \\
\hline Shineuido & 629.6 & $6,820.30$ & $16,792.30$ & 424.1 & 216.5 & $6,766.80$ & 219 & 482.9 & $32,351.50$ \\
\hline Anjwado & $1,154.40$ & $17,635.40$ & $17,020.30$ & 215.5 & $2,291.50$ & $24,467.90$ & 231.3 & $4,550.50$ & $67,566.80$ \\
\hline Amtaedo & $1,156.00$ & $14,630.80$ & $22,788.10$ & 620 & 36.9 & $22,123.50$ & 331.3 & $1,088.30$ & $62,774.90$ \\
\hline Aphaedo & $2,437.10$ & $30,856.60$ & $13,254.30$ & 700.5 & 581.9 & $57,401.00$ & 713.1 & $1,490.50$ & $107,435.00$ \\
\hline Imjado & $1,620.90$ & $16,751.70$ & $17,012.20$ & $2,304.70$ & $1,546.50$ & $10,728.20$ & $1,391.10$ & $1,297.30$ & $52,652.60$ \\
\hline Jaeundo & $1,316.80$ & $24,396.60$ & $24,071.50$ & 813.3 & 31.1 & $8,035.00$ & $2,205.00$ & 733.3 & $61,602.60$ \\
\hline Jangsando & 777 & $13,669.10$ & $9,575.40$ & 135.3 & 991.5 & $5,667.30$ & 165.8 & 789.2 & $31,770.60$ \\
\hline Jeungdo & 799.6 & $10,433.60$ & $10,762.90$ & 260 & 305 & $21,772.70$ & 726.6 & $4,090.30$ & $49,150.70$ \\
\hline Jido & $2,322.20$ & $36,060.50$ & $23,186.10$ & 512.4 & 546.7 & $37,344.10$ & 530.5 & $4,588.30$ & $105,090.80$ \\
\hline Palguemdo & 714.9 & $8,471.60$ & $6,478.30$ & 50.8 & 276.9 & $10,799.90$ & 85.5 & 881.6 & $27,759.50$ \\
\hline Haeuido & 655.1 & $8,486.80$ & $9,570.10$ & 68.3 & 448.3 & $2,056.50$ & 114 & 630.1 & $22,029.20$ \\
\hline
\end{tabular}

\section{Sustainability of TEK and Ecosystem Services}

TEK plays a very important role in maintaining sustainable ecosystem services, especially in islands. People are the core of TEK as they are the key to acquiring such knowledge, passing it on through generations, developing it and even destroying it.

According to Ellen (2007), TEK is influenced by the composition and socio-economic relations in the population for its transmission and maintenance. In addition, it is affected by various processes and forms such as social recognition and education of social members. Furthermore, the development of modern science and technology has a great impact, and also economic conditions and circumstances play a role. The knowledge itself, the factors that influence TEK and the magnitude of influence can be fundamentally different depending on whether it is, for instance, agriculture, fishing, or forestry. Knowledge delivery may also depend on the quantity and quality of resources. TEK is difficult to handle in ecosystem services because quantitative analysis through measurement and analysis is not easy (Balzan et al. 2018; Huntington 2000). However, it is a very important factor to judge the sustainability of ecosystem services.

Nowadays, islands are experiencing various problems due to rapid population decline and population aging. these problems tend to be most severe for smaller islands and smaller economies, and Shinan County is no exception. Its population has been decreasing continuously, while its elderly population has been growing rapidly (Kim 2014).

The structural changes in the population of Shinan County will have a significant impact on the transmission and maintenance of TEK and, consequently, also on its ecosystem services. The value of ecosystem services on each island 
of Shinan Country was calculated for 2012 as well as the population ratio for that year. In particular, the ratio of the population (TEKP) was calculated, and related to the value of ecosystem services (ESV) to quantify its sustainability (ESVs), as follows:

$$
E S V s=E S V \times T E K P=\sum_{k} \times \sum_{f}\left(A_{k} \times V C_{k}\right) \times \frac{Y P}{O P}
$$

Legend: $O P$ : Population members 65 years and older, $Y P$ : Population members younger than 65 years old

\begin{tabular}{|l|l|l|l|}
\hline & \multicolumn{1}{|c|}{ ESV } & \multicolumn{1}{c|}{ TEKP } & 117,411 \\
\hline Dochodo & $55,909.90$ & 2.1 & 133,955 \\
\hline Biguemdo & $58,241.50$ & 2.3 & 100,290 \\
\hline Shineuido & $32,351.50$ & 3.1 & 128,377 \\
\hline Anjwado & $67,566.80$ & 1.9 & 119,272 \\
\hline Amtaedo & $62,774.90$ & 1.9 & 290,075 \\
\hline Aphaedo & $107,435.00$ & 2.7 & 157,958 \\
\hline Imjado & $52,652.60$ & 3 & 110,885 \\
\hline Jaeundo & $61,602.60$ & 1.8 & 57,187 \\
\hline Jangsando & $31,770.60$ & 1.8 & 98,301 \\
\hline Jeungdo & $49,150.70$ & 2 & 231,200 \\
\hline Jido & $105,090.80$ & 2.2 & 47,191 \\
\hline Palguemdo & $27,759.50$ & 1.7 & 48,464 \\
\hline Haeuido & $22,029.20$ & 2.2 & \\
\hline
\end{tabular}

With the highest ESV and the third highest population ratio, Aphaedo has the highest sustainability in the value of ecosystem services. In the case of Imjado, the ESV is relatively low compared to other islands, but the population ratio is the second highest and this causes it to have the third highest sustainability, surpassing five islands with a higher ESV in ranking. Aphaedo and Jido are the two islands with the largest tidal flats and bridges connecting them to the mainland, which is likely to mitigate the demographic changes mentioned as it provides more freedom of movement. With the exception of Aphaedo and Jido, the islands in Shinan with a high population ratio (i.e., a higher percentage of workingage people) will be more likely to sustain the value of their ecosystem services. 


\section{Conclusion}

The transmission of TEK is a very important issue in island ecosystems (Hong et al. 2018). TEK is also fundamental to island ecosystem services as it can maintain or improve the value of ecosystem services (Kim 2014). Shinan County has the largest tidal flat area in Korea, which is the land cover with the highest value of ESV coefficients (Costanza et al. 1997). Aphaedo and Jido include the largest parts of tidal flat in Shinan County and, as a result, they also have the highest value of ecosystem services.

Albeit by means of introducing a simple weight factor that reflects the demographic composition of island populations in order to quantify the possibilities of transfer and acquisition of TEK in those islands, this study illustrates how additional insights into the sustainability of the value of ecosystem services could be gained. Whereas Aphaedo and Jido still ranked first and second regarding sustainability (ESVs), it was Imjado that performed better on sustainability (ESVs) than what might have been expected based on only its value of ecosystem services (ESV) due to a demographic composition that is relatively advantageous for TEK transfer and acquisition. Future research to develop the introduced weight factor into more detail seems warranted. Overall, it is important to realize that TEK can sustain the value of ecosystem services, and attempts to understand the sustainability of ecosystem services on the basis of population structure needs to be encouraged.

\section{Acknowledgements}

This paper was supported by the National Research Foundation of Korea Grant funded by the Korean Government (MEST) (NRF-2009-361-A00007).

\section{Endnotes}

1. Source: Kim, J.-E. (2014), The Value of Ecosystem Services based on Land Use in Shinangun, Jeonnam, Korea. Korean Journal of Ecology and Environment 47(3): 202-213.

\section{References}

Costanza, R., d'Arge R., de Groot R., Farberk S., Grasso M., Hannon B., Limburg K., Naeem S., O'Neill R. V., Paruelo J., Raskin R. G., Suttonkk P. and van den Belt M. 1997. The value of the world's ecosystem services and natural capital. Nature 387: 253-260.

Costanza, R., de Groot R., Braat L., Kubiszewski I., Fioramonti L., Sutton P., Farber S., and Grasso M.. 2017. Twenty years of ecosystem services: How far have we come and how far do we still need to go? Ecosystem Services 28: 1-16. 
Daily, G., Postel, S., Bawa, K. and Kaufman, Les. (1997). Nature's Services: Societal Dependence on Natural Ecosystems. Bibliovault OAI Repository, the University of Chicago Press.

Drew, J. A. 2005. Use of traditional ecological knowledge in marine conservation. Conservation Biology 19(4): 1286-1293.

Ellen, R. F. 2007. Traditional environmental knowledge in island Southeast Asia: some consequences of its demise and re-discovery for local coping strategies. (Vol. Studies in Environmental Anthropology and Ethnoecology). New York, NY: Berghahn Books.

Huntington, H.P. 2000. Using traditional ecological knowledge in science: methods and applications. Ecological Applications 10(5): $1270-1274$.

Hong, S.-K., Won, Y.-T., Lee, G.-A, Han E.-S., Cho M.-R., Park H.-Y., Kim J.-E., and Hatfield S. C. 2018. Interdisciplinary convergence research design on island biocultural diversity - case study in Woundo-gun (coungy) island region, South Korea. Journal of Marine and Island Cultures 7: 12-37.

Kim, D. K. 2010. The social capital of the fishing village and fishing village cooperatives (Eochongye) - a comparative study of three fishing villages. The Journal of Rural Society 20(1): 195-232 (in Korean with English abstract).

Kim, J.-E. 2016. Land use patterns and landscape structures on the islands in Jeonnam Province's Shinan County occasioned by the construction of mainland bridges. Journal of Marine and Island Cultures 5: 53-59.

Kim, J.-E. 2015. Rural landscape and biocultural diversity in Shinan-gun, Jeollanam-do, Korea. Journal of Ecology and Environment 38(2): 249256.

Kim, J.-E. 2014. The Value of Ecosystem Services based on Land Use in Shinangun, Jeonnam, Korea. Korean Journal of Ecology and Environment 47(3): 202-213.

Kubiszewski, I., Costanza, R., Dorji, P., Thoennes, P., and Tshering, K., 2013. An initial estimate of the value of ecosystem services in Bhutan. Ecosystem Services 3: e11-e21.

Lee, S. H. 2018. Prediction of the Korean Local Population on 2018. Employment Trend Brief 2018. July. Pp 2-21.

Balzan M. V., Potschin M., and Haines-Young R. 2016. Place-based assessment of small islands' ecosystem services. In: Haines-Young, R., Potschin, M., Fish, R., Turner, R.K.(eds.). Routledge Handbook of Ecosystem Services. Routledge Handbook Series. Routledge, London and New York, pp 140-143.

National Institute of Biological Resources. 2018. Organism story on South Western Islanders life (남도인의 삶에 깃든 생물이야기. With Korean language).

Park, J. S.. 2001. Common property and eochongye (Fishing Village Society) in a fishing village, Korea. The Journal of Rural Society 11(2): 159191 (in Korean with English abstract).

Park, M., Jeon, J. B., Choi, J. A., Kim, E. J. and Im, C. S. 2016. Analysis of ecosystem service value change using a land cover map. Korean J. Community Living Sci. 27: 681-688.

Song, K.-T. 2018. The expansion of village fisheries and the adaptation of fishing business communities (in Korean with English abstract). 